\title{
Strategic vision of planning the central area of Makkah City
}

\author{
H. Algahtani \\ College of Design, University of Dammam, Saudi Arabia
}

\begin{abstract}
The Holy City of Makkah has played a prominent international role as the sacred capital of Islam, which makes it important to review the planning of its central district, not only from the perspective of accommodation and housing, but also the strategic and religious dimension that the holy capital enjoys in the whole region. Thus, the study addresses the following question: What should be the strategic vision of the central district of the Holy City of Makkah? To answer the question, the author reviews theoretical frameworks and previous studies related to the subject matter in order to discern the principles and aspects of strategic planning as well as considerations that must be taken into account when configuring the strategic vision of the central district. The study uses a descriptive method in its documentary and screening, and a questionnaire was carried out to identify official views on the aspects and considerations that have been inferred from previous studies and related literature. There are seven main aspects out of which 45 subsets have been identified as being important to be taken into consideration when developing a strategic vision for the central istrict. The study also makes suggestions for "the central district: as a worship area with international standards" as a strategic vision suited for present and future development projects.
\end{abstract}

Keywords: Makkah, urban planning, traditional architecture, strategic planning.

\section{Introduction}

Makkah has high strategic position not only at the local level, but also at the whole Islamic world level. The fifth of the five Islam basic acts can be only performed by coming to this sacred land where The Holy Kabah and sacred rituals are located. This religious factor makes the central area in which the holy 
mosque lies an area with different planning features. On the one hand, it is the focus of pilgrims who are searching for nearby accommodation to the Holy Mosque. On the other, it is an urban environment attracted by the speed of development forces and is the meeting point of all main roads that go to Makkah. It is also a trading area where the needs of the pilgrim and minor pilgrim are served. It is fertile investment area where there is competition to invest in it, as the price of one meter in Makkah has reached half million Saudi Riyals. The adverse effect on jobs in the area has caused it to become an investment environment that is at risk of partial and random development which concentrates in certain sides and ignores others that are less important in the planning process. Each project in the area aims at achieving goals which may be contradictory or complementary whenever the development process is not performed according to a clear strategic vision that makes the whole area want to reach and achieve.

Makkah is the sacred capital of more than one billion, five hundred million muslims all around the world. Among all Saudi cities, Makkah has the highest levels of visitors from different nationalities of the world. At the local level, the percentage of touristic travels to Makkah reached 37.5\%, which is the highest percentage among all areas, exceeding Riyadh and the Eastern Province [1]. At an international level, of 1,508,000 international tourists coming to the Kingdom of Saudi Arabia, 1,207,000 tourists of them came to do pilgrimage and minor pilgrimage, which means $80 \%$ of total number. In addition, of 4,788,000 Arabian Gulf tourists coming to the kingdom, 2,427,000 tourists of them came to do pilgrimage and minor pilgrimage, which equals $50.7 \%$ of the total number of Gulf tourists [1]. Therefore, Makkah precedes other Saudi cities in attracting international and Arabian Gulf visitors, in addition to local visitors.

The Kingdom of Saudi Arabia is seen by many muslims all around the world as only Makkah. In this way, Makkah has changed from being just a city to being a cultural gateway that expresses the originality of the kingdom that uses the Islamic legislature as a method of life and civilizational advancement as both of them shall be reflected, apparently, in the planning of Makkah in general and the central area that surrounds the Holy Mosque in particular.

\subsection{Identification of the problem}

The Holy Mosque of Makkah lies in a lower point in the middle of a mountainous area which surrounds it from all sides in a close circular shape. The Holy Mosque of Makkah has been developed and has undergone many widening processes. The last and biggest one among them is the widening of the custodian of the two Holy Mosques King Fahad Bin Abdul Aziz on $1411 \mathrm{H}$ of a capacity that allows for 15,000 prayers including carpeting of the surrounding yards of the Holy Mosque with cooling marble in the total yards after widening of the custodian of the two Holy Mosques 366,108 $\mathrm{M}^{2}$ and capacity for prayers of the Holy Mosque, floors and yards 820,000 prayers. At crowd tip time, the capacity may reach one million prayers (figure 1). 


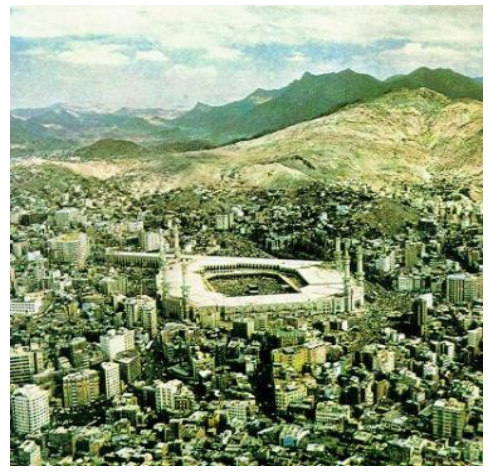

(a)

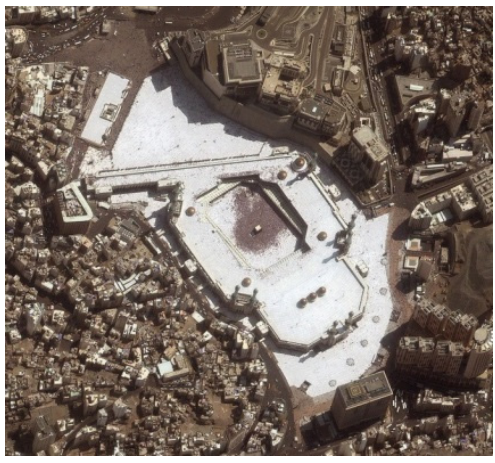

(b)

Figure 1: (a) The holy mosque before the widening and carpeting of the yards [3]. (b) The holy mosque and its surrounding yards after the widening of King Fahd.

This matter, as well as the worldwide prosperity in the fields of telecommunications and transport, led to increasing attraction and desire to do the pilgrimage as broadcasting of prayers and religious rituals in the sessions of pilgrimage and Ramadan through satellites to all countries of the world as well as the availability of air and land means of transport that facilitated traveling to Makkah from outside and inside the kingdom led to an increase of pilgrims number more than two million pilgrims while there was no more than 900,000 pilgrims 30 years ago. The number of pilgrims coming to do Umrah has increased also in the season of Ramadan to reach more than two million minor pilgrims while the number didn't exceed 300,000 30 years ago [2]. This rapid increase in the number of pilgrims and pilgrims coming to perform the Umrah showed the critical need to prepare a bigger place to contain the prayers and other places for accommodation and housing as well as providing services and facilities. According to assessments of the study of updating the structural layout of Makkah up to $1450 \mathrm{H}$, the total expected number of pilgrims on $1450 \mathrm{H}$ will be 3,900,000 which is approximately equal to 4 million pilgrims [3].

As a result of what is mentioned above, the central area in Makkah witnessed in the previous years a rapid change and announcement of huge development projects after competition of higher real estate companies to invest in the area due to the big profit return that is expected in the future. These projects had different types and multiple planning directions, most of them based on a partial basis and solutions for urgent problems that may become real planning obstacles in the future. Therefore, a general layout of the central area must be undertaken to direct the development and construction of a suitable urban environment before the problem increases and solving it becomes difficult [4].

The accommodation and housing sector in the central area have witnessed a big challenge showing a need for more hotel and seasonal rooms. According to the current standards that are applied by the Ministry of Pilgrimage that specifies the lower levels of the room to be 20 quadrate meters, the number of 
hotel and seasonal rooms of extreme capacity in pilgrimage season shall be around 780,000 rooms, while the number of hotel rooms and current seasonal housing rooms reaches around 280,000 rooms only. Based on what has been mentioned above, the total number of rooms required to be available during the following 20 years shall be around 500,000, which is a big number taking into consideration that development projects in the central area will provide only around 44,000 rooms after completion [5]. This accompanies challenges in other areas such as the need for additional places to contain the prayers, pilgrims and minor pilgrims as well as other places for providing services, facilities and finding solutions for the crowding of roads, transport and using a modern means of transport with the necessity of keeping the social and environmental infrastructures of the area without demolishing or removing if possible (Figure 2).

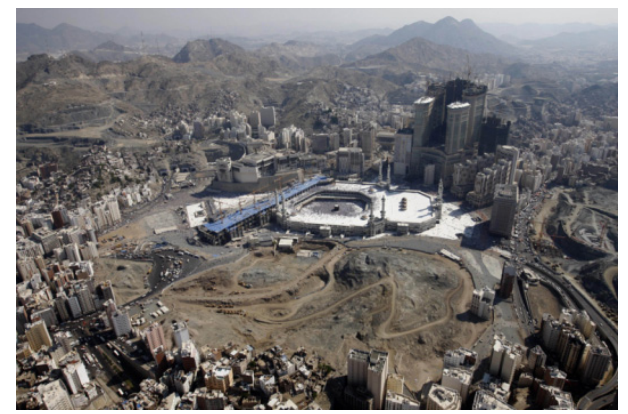

Figure 2: Upper shot of the Holy Mosque after removal of Shamia area [6]

These challenges that face the central area as the focus of movement and residence of pilgrims as well as the center of their activity through the period of their existence have shown the critical need for finding a strategic vision in developing the central area that is not immediate or partial. All sectors of projects strive to achieve it and development plans that complement and not contradict.

Therefore, this study tries to develop a strategic vision of planning the central area of Makkah through identification of sides and concerns that must be taken into consideration at the time of planning the central area in order not to develop one side against the other or exaggerate consideration and ignoring another one.

\subsection{Research questions}

General question:

How should the strategic vision of the central area of Makkah City be?

Subsidiary questions:

A - What are the factors that should be included in the strategic vision of the central area of Makkah City?

$\mathrm{B}$ - What are the considerations that form each side of the strategic vision of the central area of Makkah City? 
$\mathrm{C}$ - What is the opinion of officials and decision makers as well as planners about the importance of factors and considerations that form each aspect of the strategic vision of the central area of Makkah city?

\section{Literature review}

Planning of the central area in particular and Makkah in general underwent multiple stages to reach its current phase that can be summarized as follows:

At the beginning of the Saudi age and undertaking care of the Holy Mosque and nearby areas by the governors of the Kingdom, the first stage started in which many studies had been done to promote and develop the central area.

The first attempt was on $1391 \mathrm{H}$ which involves studying the main strategic layout that is recommended to be prepared by the Consultation Officer, Robert Mathew and it was finished on $1393 \mathrm{H}$. After that there was the study of a comprehensive development layout of Makkah on $1403 \mathrm{H}$ that was prepared by Consultation Office Engineering House, Shaer \& Partners on 1406 H. This study is considered to be one of the most comprehensive studies that has been prepared for the Makkah region as it discussed the regional, local and detailed standard of Makkah and villages as well as the gatherings that surround it.

On $1407 \mathrm{H}$, a study of the urban zone of the city was prepared including what has been done to all cities of the kingdom. This study was undertaken AlSumayet Consultation office. In fact, it wasn't a comprehensive planning study but it was a study with goals which specified drawing borders for the zone inside which the city lies up to year $1425 \mathrm{H}$ in three stages as well as specifying a limit for development protection for the lands lying between the zone limit and the limit of protecting the urban development after the year $1425 \mathrm{H}$.

As for the final planning study, it is the study of layouts of chosen work areas in Makkah, prepared by the consultation Office Ark plan in cooperation with the office of Dr Ahmed Fared Mustafa on 1413 H. It wasn't a comprehensive planning study but a detailed planning study for development of some areas of the central area in Makkah [3].

Starting from the year $1420 \mathrm{H}$ up to now:

The stage of studies and international competitions started for a complete and comprehensive development of the central area and an attempt of cooperation among a group of authorities, companies and local leaderships as well as inhabitants.

One of the earliest studies was undertaken by the Ministry of Municipality and Rural Affairs in the Ministry Secretary for Planning Cities by the participation of the Secretariat of Sacred Capital and with a group of experts and specialists as they prepared the study of the structural layout of Makkah on $1420 \mathrm{H}$.

By announcing the central area to be subject to development, the third stage witnessed studies of international competitions and studying development projects. The following are summaries of the most important projects that will be performed in the central area. 
The Omer Mountain Project is a big project for development of the area that surrounds the holy mosque that lies on 230,000 quadrate meters. The project will provide yards for prayer containing around 202,000 prayers, together with 45 hotels, 41 plots specialized for seasonal housing, 26 plots for constant housing and 2800 trading exhibits.

The Al Shamiah Project where the target area extends from the Holy Mosque building to a second circular road in the north. The suggested design is considered as a mix of group of thoughts that include widening of the northern yards of the Holy Mosque with a depth reaching 158 meters as a response to the critical need to secure wide yards for walkers separate from vehicle movement. The layout includes the design of housing buildings on a hill above Al Shamiah area; the total area forms two architectural components that are surrounding buildings and towers.

Therefore, announcing these development projects has been accompanied by a big disagreement among experts and specialists and among the benefiters and officers in the shape of research and scientific paper studies presented to local and international conferences. These studies suggested important sides and recommended the necessity of taking them into consideration at the time of planning the central area and including them in development projects that focused on seven factors: planning, religion, economics, natural, social, touristic and administrative factors.

Al-Subae and Al Barbari undertook a detailed study of housing development projects in the central area and found through the study that this development project needs review in the following aspects:

- That the central area of Makkah is placed at present on a very limited area that exceeds the first circular road slightly. Most of the projects that have been performed up to now did not take into consideration the future development of Makkah and the area of the Holy Mosque.

- There is no comprehensive vision for the development of the central area and dealing with developmental projects separately from the problems of the central area, such as transport, transportation, services and security. Projects also did not approach the way of connecting them with movement layout of the whole area either for machines or for walkers.

The study recommended the following [7]:

Zain $\mathrm{Al}$ Abidin mentioned four factors to be destructive in the development of central area, namely:

1- The very high buildings are harmful because they cut the connection of the rear areas with the continuation of their relations with the Holy Mosque and Kabah as well as the central area. There would be an increase of security, safety and transport problems especially in the vertical ones as in these very high buildings the inhabitants and pilgrims spend much time at rush times waiting their turns in lifts going up and down. There would be a loss of the original image of Makkah replacing it with the western image. 
2- Designing the overlooking on the holy mosque that leads to planning and architectural designs includes many comments such as:

- Raising the buildings above the mountains to more than 50 floors.

- Ignoring the other factors that are more important in architecture and planning (providing human housing, providing the important services that attract the citizens to reside in these sites such as schools, kindergartens, providing some gardens, providing prayer places and quick contact with the Holy Mosque and sacred rituals [8].

Therefore, a study done by the Custodian of the two Holy Mosques Institute for Pilgrimage Research requested that the big development projects in the surrounding central area be postponed until the central area is replanned. The study recommended to direct specialized authority to develop a comprehensive layout for the central area that takes into consideration the environmental and natural conditions of the area and fulfills the needs of its users with increasing the areas that are specialized for the individual as well as raising the capacity power of the Holy Mosque [9].

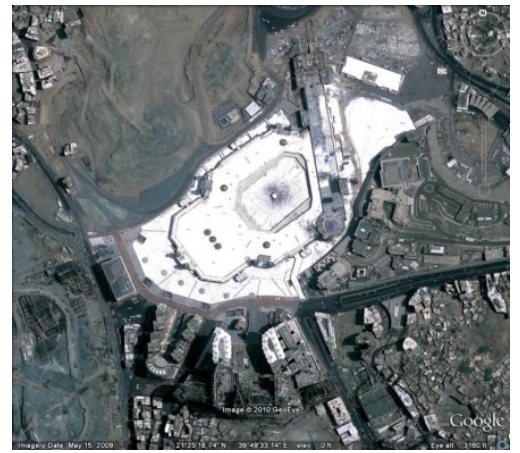

Figure 3: Aerial photo by satellite of the holy mosque area after removing works of $\mathrm{Al}$ Shamia Area and Omer Mountain Area [10].

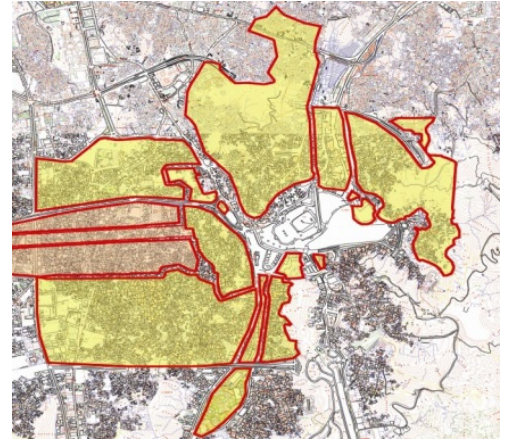

Figure 4: Site of developmental projects in the central area of the Holy Mosque [3].

The rapid increase in the number of pilgrims coming to Makkah from different places of the world will follow the announcement that there are more developmental projects providing more facilities and services to the pilgrims. This is emphasized by the statistics of the Custodian of the Two Holy Mosques Institute for Pilgrimage Research that the number of pilgrims will reach 4 million in $1450 \mathrm{H}$ and the increase of capacity power of the Holy Mosque and its yards to more than 1 million prayers at rush times, encourages more pilgrims and minor pilgrims to do their rituals and finish their religious duties.

According to assessments of the Higher Commission of Makkah Development, the number of muslims around the world has reached 1.6 billion. 
Assuming that each muslim must do the duty of pilgrimage one time in their life (as a minimum), the number of pilgrims from outside the Kingdom annually will reach $26,854,500$ [11]. Therefore, the social side of the majority of muslims has its importance that should be taken into consideration at the time of planning the central area in order to perform a just and balanced development of all categories and in order that services and facilities in the central area shall not be limited to one group against another group [12].

Makkah is a harsh mountainous terrain of igneous solid rocks and extreme heat, free of implant valley, from which Zamzam springs - the purest water on the Earth - only found in this pure land. Therefore, changing the features of this environment by removing landmarks, cutting mountains, and changing terrain without urgently needing to, carries conflict and perhaps involves risk that may not have been noticed up to now, but perhaps after hundreds of years it may be hard to avoid the consequences of some aspects which were not visible at the time. This is what has made Zain Al Abdeen [8], Subaie and Berbari [13] and Bianca [14] stress the necessity to respect the natural properties of Makkah in general and the central region in particular.

From an economical point of view, expansion by the King Fahd for AlHaram Al-Sharif, completion of the main roads to and from the central zone, construction of tunnels and facilitating travel procedures and visas for Umrah has led to an increasing number of pilgrims and the race of companies and capital investment in the central zone in Makkah is due to the growing demand for housing, facilities and services. However, these economic factors that have made the central zone grow steadily and rapidly, especially in providing high residential buildings, and associated services has led to other undesirable results, Sharif pointed out a number of them:

1 - The increase of land prices is astounding.

2- There has been a decline of individual investment, especially in the small properties, compared with capital for residential and commercial investment in the areas adjacent to Haram [4].

In a study undertaken by the Supreme Commission for Tourism of tourist aspects of the Umrah policy, a remarkable increase in the number of pilgrims from outside the Kingdom has been observed from 523,692 in $1408 \mathrm{H}$ to $2,254,322$ in $1424 \mathrm{H}$, excluding the number of pilgrims in the same year, where the study found that the average spending of these international tourists is estimated at SR. 12.8 billion making the study recommend the development of these holy places as an important attracting element which has significant economical returns [4].

It is clear from the previous studies that the central zone of Makkah City is suffering from complex and interrelated problems in different aspects and from several parties, those studies have tried, each according to his specialty to find solutions and suggestions to these problems, whether partial or general, most studies remained recommending the importance of having a comprehensive planning overview and clear strategy vision for the future of the central zone, and without the presence of this vision, the development in its current status will trend in a difficult manner, and cost of the change will become too high. 


\section{Methodology of the study}

The study has employed a descriptive methodology in both its approaches, documentary and survey, where a questionnaire was designed to identify official opinions about aspects and considerations, which have been inferred from the previous studies and related literature. Then the questionnaire applied to the entire study population, which included everyone entering the planning process of the central zone of decision-makers, officials and planners (estimated at 200 officials and experts), and despite some difficulties which were encountered in the distribution process, the response of the participants was positive and clear, where 187 questionnaire out of 200 were collected at a return rate $93 \%$. Descriptive statistics metrics have been employed using the statistical Social Sciences (spss) software package, to describe and analyze the data, and then interpreted in the light of the themes addressed by the study to achieve its goals, and display the results of those aspects if they agree, or disagree with previous studies.

The questionnaire showed that more than $38 \%$ of the study community are engineers and $15.5 \%$ are managers and $11 \%$ are consultants, while the proportion of university professors reached to $6.4 \%$ of the total sample. Years of experience of the participants are also shown, where the percentage of the participants who had more than 20 years' experience was 38, while the percentage of between 10 and 20 years' experience was $24.5 \%$, the percentage of 2 to 5 years' experience did not exceed $15 \%$.

\section{Results of the study}

The following are the most important findings of the study according to its goals. It is through a review of theoretical frameworks and previous studies, which included global and local experiments in the planning and development of historical significance or cultural areas that the study found 111 considerations distributed on seven key aspects (the religious aspect/planning/administrative /natural/social/tourism/economics).

Through analyzing the information gathered from officials, decision-makers, and planners about the importance of aspects and considerations that should be included in the formation of a strategic vision of the central zone of Makkah City, the study concluded the descending order of these points starting with planning aspects and ending with the economic aspect. Then considerations were classified into four classifications, a very important consideration got greater weight greater than the sum of (total average of weights + standard deviation). Important considerations that got the weights above the overall average of the weights, and average considerations that got weights under the overall average of the weights, and low considerations that got weight below of (the overall average weight - standard deviation). 


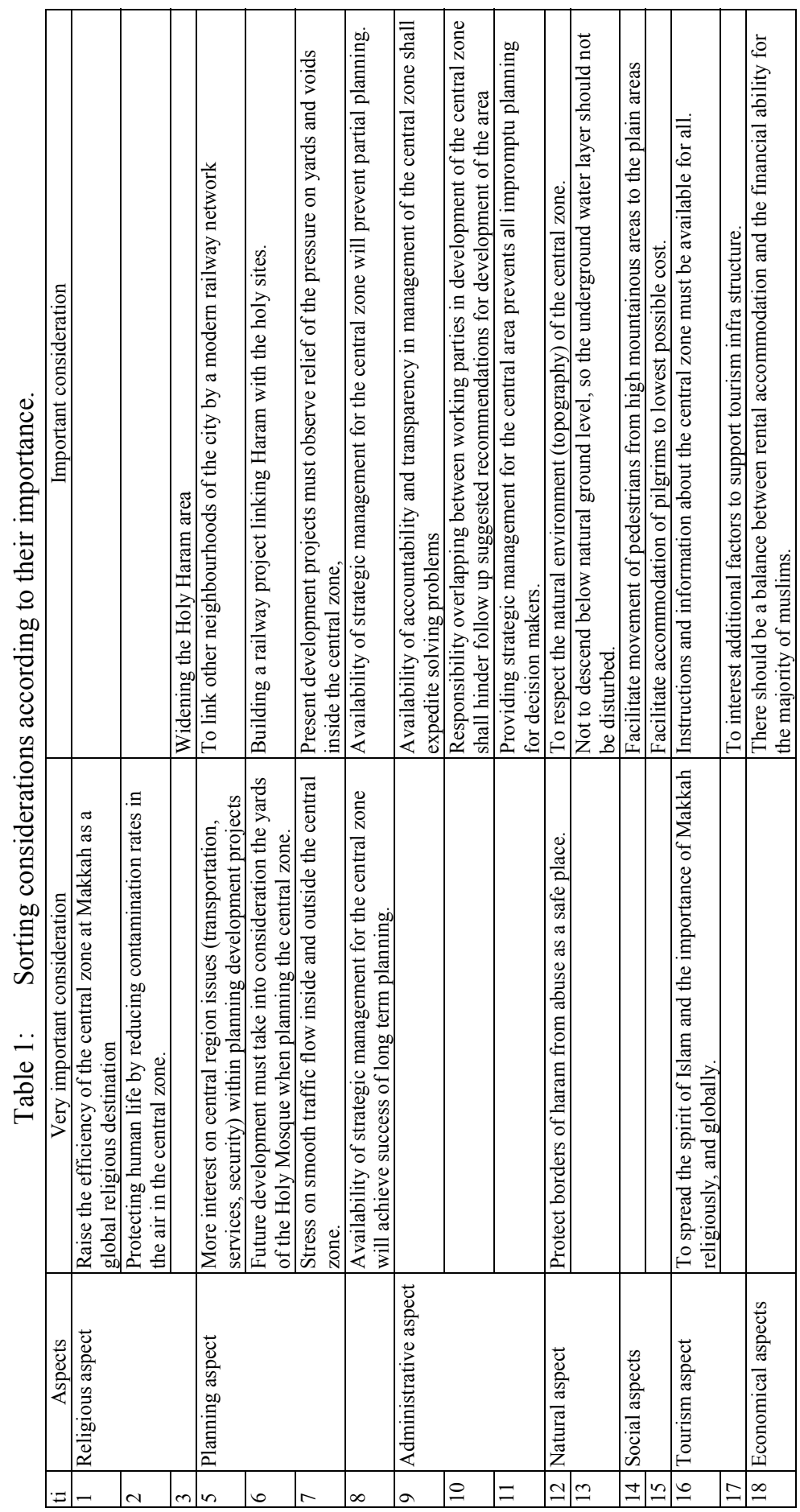




\section{Strategic vision of the central zone of Makkah City}

Based on the above of the previous studies and the results that have been drawn from the data and information gathered from the study population, detailed aspects of the formulation of the strategic vision of the central zone have been identified in order to answer the main question posed by the study:

\subsection{How should the strategic vision of the central zone of the City of Makkah be?}

In the light of these results the study reached the proposed strategic vision, where its procedural steps will be reviewed as follows:

\subsubsection{Procedural steps to formulate the strategic vision for the central zone oftrategic vis}

Culminating all the above considerations, the religious side achieved the highest level of importance, far ahead of other considerations. The consideration of raising the efficiency of the central zone of Makkah as a global religious destination, 168 out of 187 answered as very important, i.e. $90 \%$ of the study population, which included planners, officials and decision makers influencing the planning process agree on the serious importance that should be handled by the central zone to raise their efficiency not as a commercial and consumer zone, but as a religion destination of Islam and muslims and with clear features interacting with visitors and fulfilling their needs and enabling them to do what they have travelled distances to do without concern or hindrance; that to be enhanced by the selection of participants for the second consideration in terms of importance, namely protection of human life by reducing rates of air pollution in the central zone, and the third consideration which is the expansion of the Holy Haram area, where the two selections confirmed that human safety for pilgrims and the protection of their experience in this holy land from disease and pollution, to be able to complete rituals easily, smoothly and safely is one of the first rights that should be honoring them and to be taken into account when setting out planning and architectural and urban standards for this area in particular.

These 21 considerations chosen by the participants to be of serious importance among the 45 considerations, all of which revolved around the conviction of participants by 5 pillars of all considerations can be returned to:

1 - The importance of the development of the central zone on the basis of upgrading as a global religious destination.

2 - The importance of pilgrims and visitors in their different levels are the source of inspiration for the planning process.

3 - Mastering and improving the quality of services provided to pilgrims.

4 - Preserving the nature of the Holy Land by using the principles of sustainable development. 
5 - A collection all of them under the strategy management umbrella having a clear strategic vision to meet all the above.

The first and second pillars can be entered in one context and that is to declare the central zone worship area as a specific goal that central zone with all its categories seeks to achieve, through which the upgrading of its efficiency as a global religious destination of Islam, and the adaptation of the planning process in the central zone to be at the pilgrims' service in the first place, and the third, fourth, and fifth pillars can be entered in one context, which is to achieve international standards in this zone, including mastery and development of the quality of services provided to pilgrims and visitors, through the use of strategic management of all sectors, in addition to maintaining the nature of the Holy Land, through rationing the principles of sustained development.

The strategic vision to be formulated into one sentence from the requirements of these considerations.

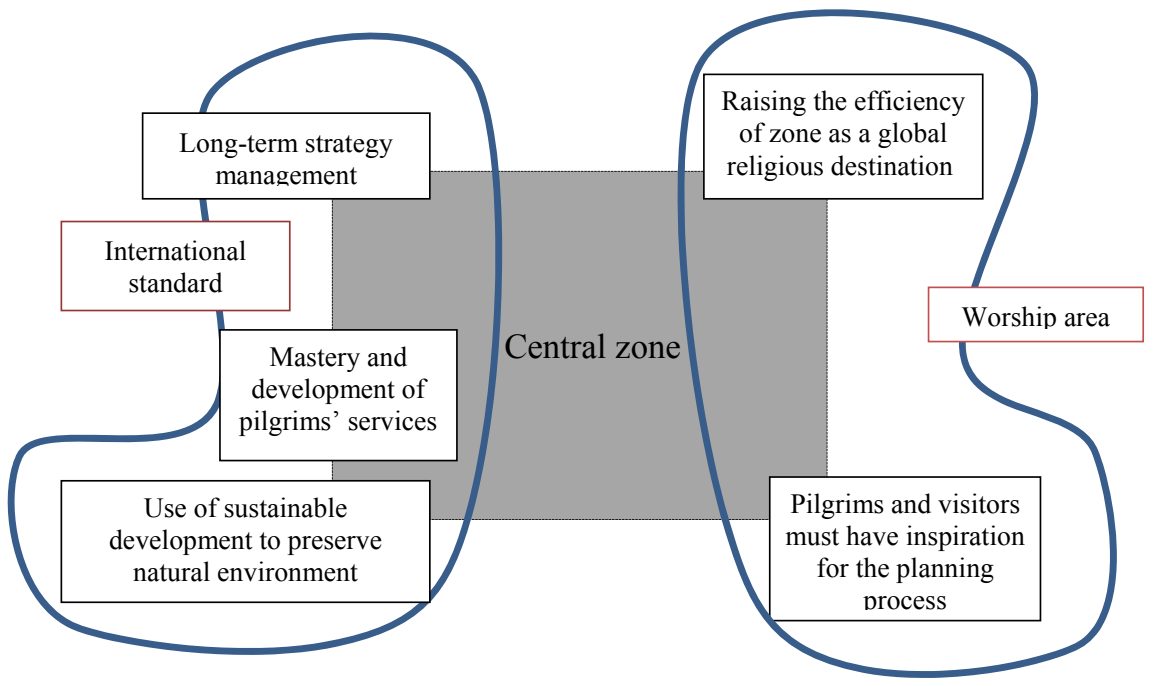

Figure 5: Directions of requirements to develop a strategic vision for central zone planning.

\subsection{The central zone as a worship area with international standard}

In order to achieve the strategic vision and realistic in optimize manner the following steps should be taken:

- Formation of management committees and the distribution of work teams.

- Review and evaluate the current situation of the city.

- determine risk and expected opportunities for growth on present and future of the central zone future.

- Review formulation of the strategic vision of the Central Zone and its relevance to reality and aspirations by answering questions such as:

- How central zone will be after 50 years? 
- Is the central zone growth will continue over the coming decades with the same dynamic and method as it was during the past twenty years?

- Is there an optimum size for the Central Zone must stand must stop at it?

- How will the Holy Capital City of the Kingdom of Saudi Arabia perform its function? And whether the Central Zone will be mainly a zone of religious activities related to Hajj and Umrah or will expand in its functions?

- Committees shall begin work to achieve the strategic vision through dismantling it to procedural steps for each side of the constituent aspects of the vision, which the base formed to build it.

\section{References}

[1] Higher Commission of Tourism, 2004, Tourism Aspects in Umrah System, Gen. Secretariat for Higher Commission of Tourism, Riyadh, Kingdom of Saudi Arabia.

[2] Fekri, Mohammed, Sawi, Mohammed, 2007, Road to Makkah between Problems and Hope towards Future Vision for main traffic of Holy haram, 14th Annual Forum for Saudi Society for Urban Science, Makkah.

[3] Higher Commission for Makkah Development, 1425, Modernizing Structural Plan of Makkah City 1450, Jeddah.

[4] Sharif, Mohammed Musalat, 2003, Factors affecting in planning Central Zone of Makkah, King Abdul Aziz University Magazine, Environmental Designs.

[5] Secretariat of Makkah and Madinah Commission, and Holy sites, 1428, Current Status for management of Urban and rates of Planning for Makkah and Madina, Kingdom of Saudi Arabia.

[6] http://www.makkawi.sa/

[7] Mustafa, Waleed, Sharif, Faisal, 2007, Urban Transitions of Makkah between Tradition and Modernity, 14th Annual Forum for Saudi Society for Urban Science, Makkah.

[8] Zain Al Abdeen, Habib, 2007, Proper planning is not incompatible with the investment in Central Zone in Makkah, Building Technology Magazine, Ministry of Municipality \& Rural Affairs, Volume Nine.

[9] Idris, Mohammed Abdulla, 1426, Study of development the Northern Yards of the Holy Mosques, Custodian of Two Holy Mosques Institute for haj Researches, Um Al Qura University, Makkah.

[10] www.Googlearth.com

[11] Higher Commission for Makkah Development, 1424, Custodian of Two Holy Mosques Institute for Haj Researches, Analyzing economical impacts of great real estate projects proposed for construction in Makkah, Jeddah.

[12] Fadaaq, Tariq, 2002, Development of Central Zone plan around Holy Mosque during 20 years, Global Conference about King Fahad Bin Abdul Aziz and his Achievements, Ministry of Higher Education, King Saud University, Riyadh, KSA. 
[13] Subaie, Ibrahim, Berbari, Awad, 2007, Features and indicators of the current status of land use and housing in Makkah, 14th Annual Forum for Saudi Society for Urban Science, Makkah.

[14] Bianca, Stephano, 2000, Urban Form in the Arab World, Thames \& Hudson, U.K.

[15] Berhmin, Sami Yasin, 2007, Updated Structural Plan for Makkah City and Central Zone Study, 14th Annual Forum for Saudi Society for Urban Science, Makkah.

[16] Mustafa, Mohsen, Abu Auwf, Tarique, 2007, Urban and Architectural challenges of Central Zone projects, 14th Annual Forum for Saudi Society for Urban Science, Makkah.

[17] Haj Research Center, 1396, Makkah: Policy Framework and Future Development, King Abdul Aziz University, Jeddah, Saudi Arabia. 